\title{
Mechanisms determining the behaviour of the left atrial pressure during cardioplegia
}

\author{
J. BRUCE JOHNSTON, G. R. PRITCHARD, AND J. S. WRIGHT \\ From the Department of Cardiopulmonary Surgery, University of New South Wales, Sydney, Australia
}

The technique of inducing profound hypothermia by peripheral cannulation in man without opening the chest and using a heart-lung machine does not permit the surgeon to vent the left side of the heart (Woodhall, Sealy, Hall, and Floyd, 1960 ; Patterson and Ray, 1962). In open-heart surgery this is considered to be a vital step in preventing dilatation of the left heart and the pulmonary vasculature from continuing bronchial venous return. Indeed, if this is not done, in particular in the repair of defects with a large bronchial circulation, e.g., tetralogy of Fallot, the left heart may be irreversibly damaged by distension and the pulmonary vasculature may likewise be damaged beyond repair. This latter state was considered to be one of the most potent causes of the perfusion lung syndrome in the early days of bypass. Nevertheless when this method is used to produce profound hypothermia when operating on intracranial aneurysms little difficulty is experienced in reversing ventricular fibrillation to sinus rhythm, and post-operatively cardiopulmonary difficulties are minimal (Patterson and Ray, 1962 ; Michenfelder, Kirklin, Uihlein, Svien, and MacCarty, 1964 ; Gonski, Johnston, Hercus, Rollison, and Nield, 1964 ; Gonski and Johnston, 1966).

Earlier studies which we performed (Johnston, Nield, Pritchard, and Hercus, 1965), when direct measurement of the left atrial pressure was made using a modification of the Ross (1959) technique, showed that at normal flow rates of $60 \mathrm{ml} . / \mathrm{kg}$. / min., although the left atrial pressure rose, it did not reach dangerous levels. When the flow was artificially increased to $120 \mathrm{ml} / \mathrm{kg}$. $/ \mathrm{min}$. by transfusion, the left atrial pressure rose still further, but again the level was tolerable. It was of interest that the highest left atrial pressures were attained during the period before fibrillation, due presumably to the failing left ventricle being unable to eject its contents against the perfusion pressure. For this reason it is now our practice

'Supported by a grant from the National Heart Foundation, in operations on patients to fibrillate the heart deliberately at 28 to $30^{\circ} \mathrm{C}$. The left atrial pressure then falls and the venous return is augmented, allowing more rapid cooling to take place. In a further group of animals when the period of cardioplegia with a circulation was greatly prolonged, the animals all regained consciousness, and, although several died in the early postoperative period, the deaths were not attributable to cardiopulmonary failure.

The mechanism determining the behaviour of the left atrial pressure during cardioplegia when bronchial return is continuing was hinted at by Ross, Gilbert, Sharp, and Morrow (1958). They suggested that the left heart might be being decompressed through the lungs and then, by means of the incompetent pulmonary and tricuspid valves, into the systemic venous reservoir. The following group of experiments was undertaken to determine whether this indeed was the mechanism involved.

\section{MATERIAL AND METHODS}

Healthy mongrel dogs, weighing between 20 and 30 $\mathrm{kg}$., were anaesthetized with nembutal $(60 \mathrm{mg} . / \mathrm{kg}$.) given intravenously. The animal was then intubated under direct vision using the largest possible Magill's tube. Anaesthesia was maintained with oxygenenriched air supplemented with nitrous oxide. The gas mixture was given through a circle absorber and the dog was placed on controlled ventilation using a Jefferson ventilator. Controlled respiration was continued until ventricular fibrillation developed spontaneously or was induced, and was resumed if the animal was rewarmed and defibrillated.

Catheters were then introduced into the right femoral artery and the left external jugular vein for monitoring arterial and venous pressures. As in the previous experiments, profound hypothermia was induced using peripheral cannulation. The left common iliac vessels were then exposed, the vein to provide the venous drainage and the artery to accept part of the arterial return. The left common carotid artery was also exposed to accept the remainder of 
the arterial return and provide more even cooling before fibrillation.

A left thoracotomy was then performed through the fifth intercostal space and the pericardium was opened. The pulmonary artery was dissected out and a tape passed around it so that it could be clamped at will. A catheter was introduced into the left atrium through a pulmonary vein, and a similar catheter was introduced into the pulmonary artery distal to the point where it was going to be clamped. These catheters were held in place by purse strings of $5 \times 0$ silk inserted through the adventitia only. Great care was taken to make sure that anchorage was secure and that no leakage would occur around the catheter.

The heart-lung machine, a rotating disc oxygenator, was primed with $1,000 \mathrm{ml}$. normal saline and 1,500 ml. fresh heparinized blood ; $5 \% \mathrm{CO}_{2}$ in oxygen was used in the oxygenator.

The animal was given $3 \mathrm{mg}$. heparin $/ \mathrm{kg}$. intravenously. The largest possible plastic catheter was inserted into the external iliac vein and pushed well up into the vena cava. The external iliac and the common carotid arteries were cannulated with metal cannulae and the animal was connected to the heart-lung machine. Temperatures were recorded from the venous reservoir and the arterial filter beyond the heat exchanger, and in the animal from the pharynx, oesophagus, and rectum.

Bypass and cooling were begun. The flow rate was regulated to maintain the extracorporeal volume constant, but this was overridden if the blood pressure fell, and the animal was then transfused. It was determined to maintain a systemic pressure of over $70 \mathrm{~mm}$. $\mathrm{Hg}$ and to maintain the venous pressure as constant as possible. The temperature difference between the blood going into and coming out of the machine was not allowed to exceed $10^{\circ} \mathrm{C}$. Three different series of animals were studied.

SERIES 1 Four animals were studied. The temperature was lowered to $30^{\circ} \mathrm{C}$. pharyngeal, at which point ventricular fibrillation was induced electrically. Ten minutes was allowed for the circulation to stabilize. A clamp was then applied to the pulmonary artery and this was kept in position for 30 minutes, during which time the various pressures were recorded. The clamp was then released slowly over a period of three minutes, and the fall in the left atrial and pulmonary artery pressures was noted. After a further 10 minutes the heart was defibrillated.

SERIES 2 Four animals were again studied and the procedure outlined for the first series was followed precisely, except that the temperature was lowered to $20^{\circ} \mathrm{C}$. pharyngeal. If fibrillation had not occurred spontaneously before this temperature was reached, it was induced electrically at this temperature.

SERIES 3 In this group of four animals the temperature was lowered to $10^{\circ} \mathrm{C}$. before application of the clamp after ventricular fibrillation had occurred spontaneously or had been induced.
In each series two control experiments were 음 performed. The protocol was followed precisely in 흘 every detail, except that the pulmonary artery was $\frac{\overline{\mathcal{C}}}{\frac{}{\sigma}}$ allowed to remain unclamped during the half-hour $\mathbb{D}$ period after induction of fibrillation at the prescribed temperature.

In each experiment the adequacy of the perfusion $\overrightarrow{0}$ was checked by repeated estimations of arterial and venous $\mathrm{O}_{2}$ saturation, $\mathrm{Po}_{2}, \mathrm{PCO}_{2}$, acid base balance, $\vec{\omega}$ and by measurement of the pyruvic and lactic acid contents of the venous blood.

\section{RESULTS}

The return of blood to both the external iliac and common carotid arteries provided even cooling of 윽 the animal at a rate of approximately $1^{\circ} \mathrm{C}$. per minute in the period before fibrillation. This $Z$ obviated the situation encountered in earlier experiments, where only the external iliac artery 3 was used for arterial return, and a large gradient $\mathbb{\Phi}$ developed between the upper and lower parts of the body before the onset of ventricular fibrillation.

Table I shows the mean left atrial pressure at various times during the experiment on the first series of animals. The figures in parentheses are the mean venous pressures at corresponding times.

T A B L E I

LEFT ATRIAL PRESSURE (mm. Hg) AT $30^{\circ} \mathrm{C}$.

\begin{tabular}{|c|c|c|c|c|}
\hline Dog & $\begin{array}{l}\text { Pre- } \\
\text { fibrillation }\end{array}$ & $\begin{array}{l}\text { Pre- } \\
\text { clamping }\end{array}$ & $\begin{array}{l}\text { After } 30 \mathrm{~min} . \\
\text { Clamping }\end{array}$ & $\begin{array}{l}\text { Release of } \\
\text { Clamp }\end{array}$ \\
\hline \multirow[t]{2}{*}{$\begin{array}{l}\text { A1 } \\
\text { A2 } \\
\text { A3 } \\
\text { A4 }\end{array}$} & $\begin{array}{r}8(4) \\
18(9) \\
15(5) \\
17(7)\end{array}$ & $\begin{array}{l}21(5) \\
17(8) \\
16(6) \\
23(20)\end{array}$ & $\begin{array}{l}61(5) \\
32(9) \\
42(20) \\
42(16)\end{array}$ & $\begin{array}{l}14(6) \\
23 *(8) \\
23(18) \\
30^{*}(16)\end{array}$ \\
\hline & $\begin{array}{c}\text { Pre- } \\
\text { fibrillation }\end{array}$ & Fibrillation & $\begin{array}{c}\text { After } \\
30 \mathrm{~min} .\end{array}$ & \\
\hline $\begin{array}{l}\mathrm{Cl} \\
\mathrm{C} 2\end{array}$ & $\begin{array}{r}14 \\
9\end{array}$ & $\begin{array}{l}12 \\
10\end{array}$ & $\begin{array}{l}12 \\
19\end{array}$ & \\
\hline
\end{tabular}

It will be noted that after a period of clamping for 30 minutes the mean left atrial pressures $N$ reached levels varying from 32 to $61 \mathrm{~mm}$. $\mathrm{Hg}$. This was accompanied by gross distension of the left ventricle and the left atrium. On release of $\mathrm{\omega}$ the clamp there was a fall in the left atrial pressure in every instance. In $\mathrm{A} 1$ and $\mathrm{A} 3$ this was substantial and the relationship to venous pressure compared with the relationship before clamping was at least re-established. In A2 and A4 the fall was not so marked. Furthermore, the pulmonary artery pressures were equal to the left atrial pressures but well in excess of the venous pressures. The clamp had been released suddenly 


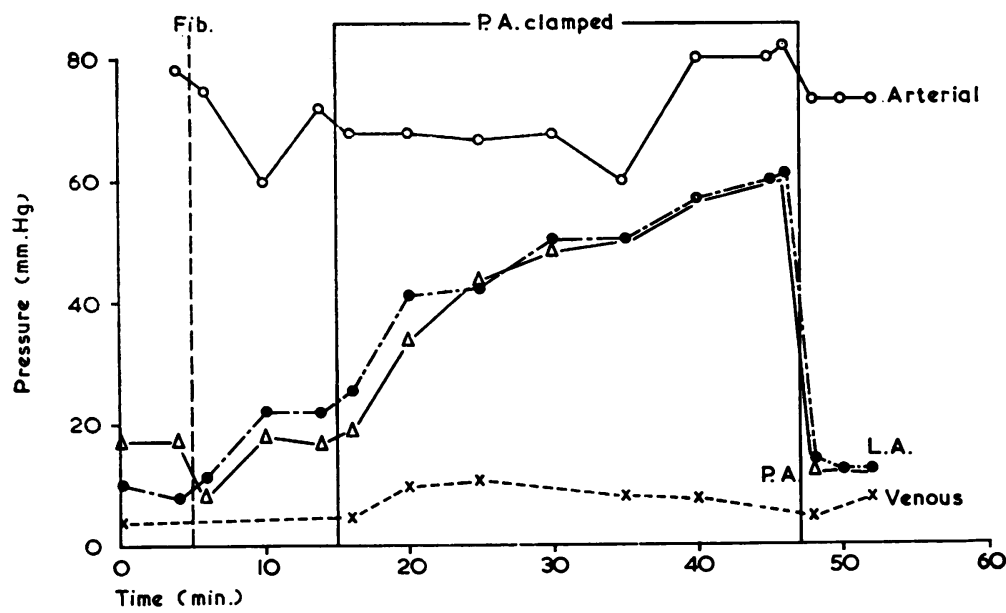

FIG. 1. Left atrial pressure in $\operatorname{dog} A 1$ cooled to $30^{\circ} \mathrm{C}$. Note the fall on release of the clamp on the pulmonary artery.

in these two animals and it seemed that the sudden rush of blood had rendered the pulmonary valve competent. This led to a modification in technique, and thereafter the clamp was released slowly over a period of three minutes. The left atrial pressure in the two control animals did not vary appreciably throughout the experiment.

Figure 1 is a graphic representation of the behaviour of the various pressures in A1. It will be noted that the relationship of left atrial and pulmonary artery pressures is reversed after fibrillation, and this in turn would allow for a reversal in flow.

T A B L E I I

LEFT ATRIAL PRESSURE (mm. Hg) AT $20^{\circ} \mathrm{C}$.

\begin{tabular}{c|c|c|c|c}
\hline Dog & $\begin{array}{c}\text { Pre- } \\
\text { fibrillation }\end{array}$ & $\begin{array}{c}\text { Pre- } \\
\text { clamping }\end{array}$ & $\begin{array}{c}\text { After 30 min. } \\
\text { Clamping }\end{array}$ & $\begin{array}{c}\text { Release of } \\
\text { Clamp }\end{array}$ \\
\cline { 1 - 2 } A5 & $11(6)$ & $16(14)$ & $35(11)$ & $12(10)$ \\
A6 & $14(8)$ & $12(8)$ & $24(8)$ & $12(7)$ \\
A7 & $5(3)$ & $14(3)$ & $28(5)$ & $22 *(6)$ \\
A8 & $9(8)$ & $4(3)$ & $17(5)$ & $7(5)$ \\
\hline & $\begin{array}{c}\text { Pre- } \\
\text { fibrillation }\end{array}$ & Fibrillation & $\begin{array}{c}\text { After } \\
30 \text { min. }\end{array}$ & \\
\hline C3 & 15 & 17 & 23 & \\
C4 & 9 & 8 & 7 & \\
\hline
\end{tabular}

* R.V. $=21$.

Table II shows the changes in the left atrial pressures in the second series of animals which were cooled to $20^{\circ} \mathrm{C}$. Again the pressure rose in every instance during the period of clamping, but the ultimate pressures were much more modest, varying from 17 to $35 \mathrm{~mm}$. $\mathrm{Hg}$. There was an appreciable fall on release of the clamp except in A7. In this animal the clamp was inadvertently released too quickly. It was noted that the right ventricular pressure was about the same as the left atrial and pulmonary artery pressures, and presumably the tricuspid valve had become competent with the sudden rush of blood.

Once more, in the control animals, the left atrial pressure did not vary significantly during the experiment.

Figure 2 shows the pressures in A8 when the left atrial pressure rose only to $17 \mathrm{~mm}$. $\mathbf{H g}$ during the period of clamping. This was in spite of a good arterial pressure being maintained. The preparation was checked repeatedly for leaks, but none was found.

Figure 3 shows the pressures in A7 when a fall did not occur on releasing the clamp.

Table III shows the behaviour of the left atrial pressures in the animals cooled to $10^{\circ} \mathrm{C}$. Here the rise in pressure was most impressive, the ultimate pressure varying from 43 to $95 \mathrm{~mm}$. $\mathbf{H g}$. There was a marked drop in pressure in each experiment on releasing the clamp and in all animals the venous left atrial pressure relationship before clamping was at least re-established. Again the two control animals showed no appreciable

T A B L E I I I

LEFT ATRIAL PRESSURE (mm. $\mathrm{Hg}$ ) AT $10^{\circ} \mathrm{C}$.

\begin{tabular}{c|c|c|c|c}
\hline Dog & $\begin{array}{c}\text { Pre- } \\
\text { fibrillation }\end{array}$ & $\begin{array}{c}\text { Pre- } \\
\text { clamping }\end{array}$ & $\begin{array}{c}\text { After 30 min. } \\
\text { Clamping }\end{array}$ & $\begin{array}{c}\text { Release of } \\
\text { Clamp }\end{array}$ \\
\cline { 1 - 2 } A9 & $11(8)$ & $15(4)$ & $48(4)$ & $17(6)$ \\
A10 & $18(4)$ & $15(4)$ & $95(6)$ & $12(6)$ \\
A11 & $18(3)$ & $26(2)$ & $74(4)$ & $26(4)$ \\
A12 & $16(10)$ & $22(10)$ & $43(18)$ & $17(10)$ \\
\hline & $\begin{array}{c}\text { Pre- } \\
\text { fibrillation }\end{array}$ & Fibrillation & $\begin{array}{c}\text { After } \\
\text { C5 min. }\end{array}$ & \\
\hline C5 & 4 & 9 & 11 & \\
\hline C6 & 8 & 7 & 8 &
\end{tabular}




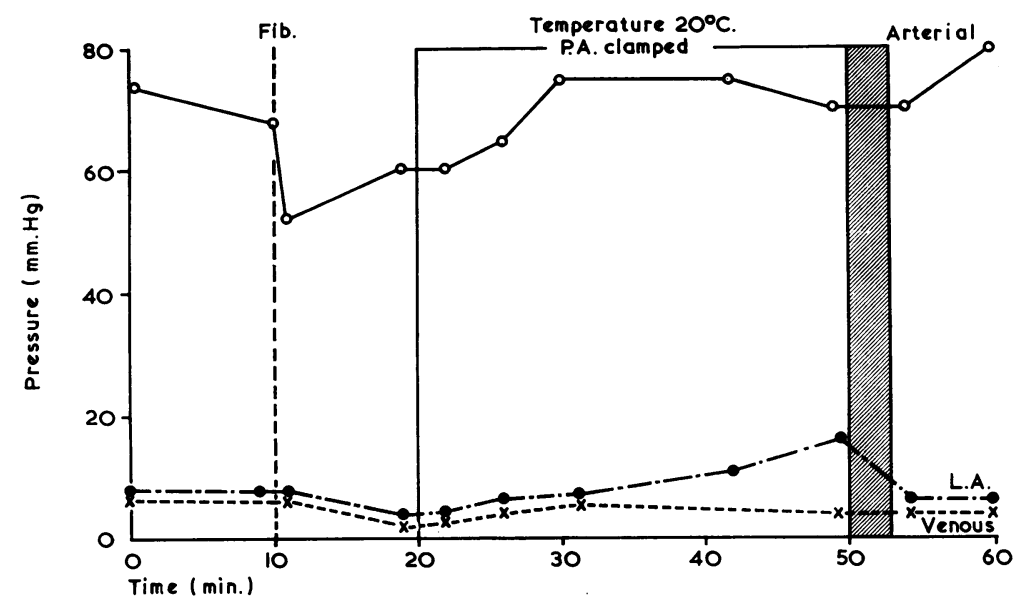

FIG. 2. Pressures in dog A8 cooled to $20^{\circ} C$. The rise in left atrial pressure was very small in spite of an adequate systemic arterial pressure.

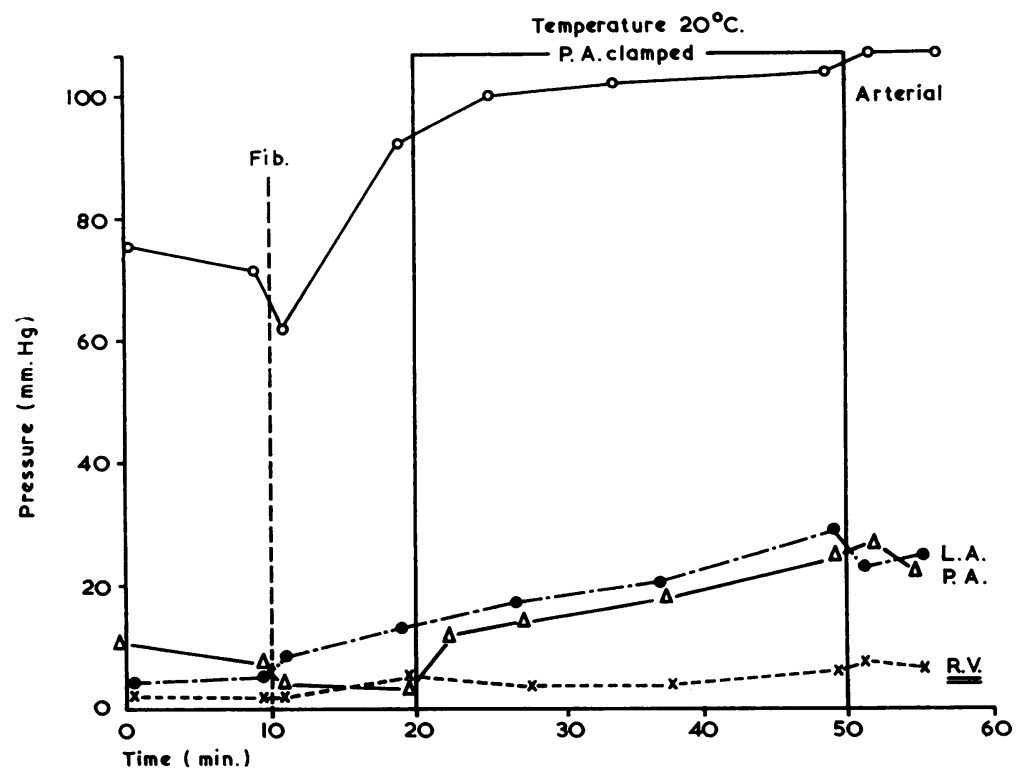

FIG. 3. Pressures in $\operatorname{dog} A 7$. Here the fall in left atrial pressure was minimal on releasing the clamp, but the right ventricular pressure was similar to the pulmonary artery pressure.

variation in left atrial pressure during the experiment.

Figure 4 shows the behaviour of the pressures in A11.

In Table IV the systemic pressure just before releasing the clamp is compared with the maximum left atrial pressure. It will be noted that it was possible to maintain an adequate systemic pressure of $70 \mathrm{~mm} . \mathrm{Hg}$ or more in both series 1
T A B LE IV

RELATIONSHIP OF SYSTEMIC PRESSURE TO MAXIMUM LEFT ATRIAL PRESSURE ON CLAMPING

\begin{tabular}{c|c|c}
\hline \multicolumn{3}{|c}{ Hypothermia } \\
\hline $30^{\circ} \mathrm{C}$. & $20^{\circ} \mathrm{C}$. & $10^{\circ} \mathrm{C}$. \\
\hline $80: 61$ & $60: 35$ & $90: 48$ \\
$80: 32$ & $64: 24$ & $90: 92$ \\
$70: 32$ & $105: 28$ & $80: 74$ \\
$70: 44$ & $65: 17$ & $90: 43$ \\
\hline
\end{tabular}




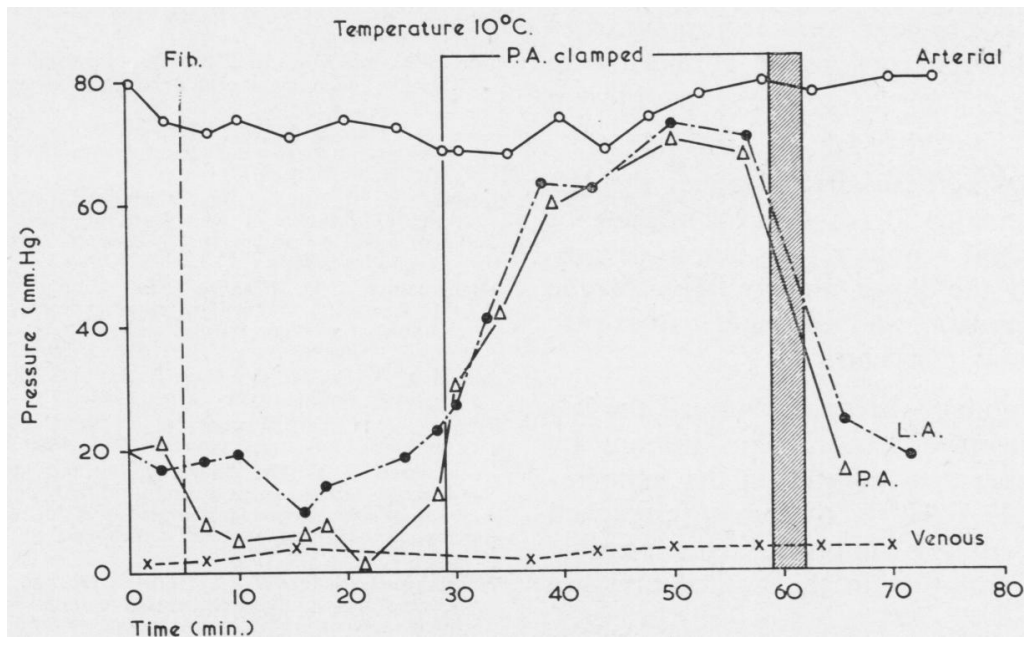

FIG. 4. Pressures in $\operatorname{dog}$ A 11 cooled to $10^{\circ} \mathrm{C}$. After clamping the pulmonary artery for $30 \mathrm{~min}$. the left atrial pressure rose to almost systemic levels.

and 3. Some difficulty was experienced in series 2 , where the left atrial pressure rose least. In the animals cooled to $10^{\circ} \mathrm{C}$., excellent systemic pressures could be maintained without difficulty and with minimum transfusions.

\section{DISCUSSION}

It seems reasonable to conclude in the context of the above experiments that, during cardiopulmonary bypass, when peripheral cannulation is used, the cardioplegic heart is decompressed through the incompetent pulmonary and tricuspid valves into the caval reservoir and thence to the heart-lung machine. In every one of the experiments, which were adequately controlled, the left atrial pressure rose when this route was blocked. Furthermore, the left atrial pressure would drop and re-establish the relationship to the venous pressure on release of the clamp, provided this was done slowly. When ventricular fibrillation was induced the relationship of the pulmonary artery pressure to the left atrial pressure would be reversed, providing a flow gradient between the left atrium and the pulmonary artery.

Nevertheless it is well recognized that severe damage can be done to the heart and lungs during cardioplegia when patients are undergoing open heart surgery unless some mechanical venting is provided for the left heart. This is particularly true in cyanotic heart disease, where the bronchial flow is greatly increased and may reach 20 to $30 \%$ of the systemic output. In these circumstances it is likely that the back flow through the pulmonary artery is so great that the pulmonary or tricuspid or both valves are closed by the tide. In normal hearts the flow is much less and probably amounts to a trickle going back through the pulmonary valve.

Another point which must be commented on is the difference in the rise of the left atrial pressure on clamping at the three different temperatures in the above experiments. It seems that this can only be related to different volumes of bronchial flow at the three different temperatures and is presumably related to alteration in vascular tone in the bronchial arteries. In the group of animals cooled to $10^{\circ} \mathrm{C}$., in two instances the left atrial pressure reached virtually systemic pressures and presumably the bronchial arteries are wide open. If alteration in tone is the explanation, then at $20^{\circ}$ C. one would assume that the bronchial vessels are in spasm. Yet this does not correlate with the behaviour of the systemic pressures in these two groups. Difficulty was experienced in maintaining a systemic pressure in the animals cooled to $20^{\circ} \mathrm{C}$., whereas a high systemic pressure could be maintained with ease in the animals cooled to $10^{\circ} \mathrm{C}$. This suggests a converse behaviour of the arterial system generally compared with the bronchial vessels. This subject deserves further investigation.

\section{SUMMARY}

An investigation has been made of the mechanisms determining the behaviour of the left atrial 
pressure during cardioplegia on cardiopulmonary bypass. Three different groups of animals were studied and each group was cooled to a different temperature.

It appears that in these circumstances the left atrial pressure remains at a low level in spite of continuing bronchial venous return due to decompression through the lungs and by way of the incompetent pulmonary and tricuspid valves into the systemic venous reservoir.

When the pulmonary artery is clamped the left atrial pressure invariably rises. The amount by which it rises appears to depend on the temperature of the animal. At $10^{\circ} \mathrm{C}$. the pressure reached systemic levels in two animals. The possible reasons for this variation in the rise of pressure are discussed.

\section{REFERENCES}

Gonski, A., and Johnston J. B. (1966). Profound hypothermia as an adjunct in the management of intracranial aneurysms. Pac. Med. Surg. (in the press).

- Hercus, V. M., Rollison, R. A., and Nield, J. (1964). Profound hypothermia for intracranial surgery: case report.

Johnston, J. B., Nield, J. M., Pritchard, G. R., and Hercus, V. M. (1965). Studies of left atrial pressure during cardioplegia produced by profound hypothermia using the closed chest technique. Thorax, 20, 234.

Michenfelder, J. D., Kirklin, J. W., Uihlein, A., Svien, H. J., and $\omega$ MacCarty, C. S. (1964). Clinical experience with a closed-chest method of producing profound hypothermia and total circulatory arrest in neurosurgery. Ann. Surg., 159, 125.

Patterson, R. H., Jr., and Ray, B. S. (1962). Profound hypothermia N for intracranial surgery. Ibid., 156, 377.

Ross, J., Jr. (1959). Transseptal left heart catheterization: A new $O$ method of left atrial puncture. Ibid., 149, 395.

- Gilbert, J. W., Jr., Sharp, E. H., and Morrow, A. G. (1958). $\rightarrow$ Elective cardiac arrest during total body perfusion: The relation-o ship of elevated intracardic pressures during arrest to subsequent myocardial function and pathologic pulmonary changes. $J$. myocardial function
thorac. Surg., 36, 534 .

Woodhall, B., Sealy, W. C., Hall, K. D., and Floyd, W. L. (1960). Craniotomy under conditions of quinidine-protected cardioplegia and profound hypothermia. Ann. Surg., 152, 37. 